\title{
Tecnologia assistiva de baixo custo no atendimento de alunos com deficiência física
}

\section{Assistive technology low cost on call of students with physical disabilities}

\begin{abstract}
RESUMO: O objetivo deste trabalho foi inserir recursos e procedimentos da tecnologia assistiva no atendimento de alunos com deficiência física. Participaram dois alunos com idades entre 17 e 19 anos, com diagnóstico de encefalopatia crônica não progressiva, sem alterações cognitivas, auditivas e visuais, sem linguagem oral. Os alunos frequentam sala de recurso multifuncional, atendimentos fonoaudiológicos e musicoterapia em um Núcleo de Apoio Integrado ao Atendimento Educacional Especializado. A coleta ocorreu no período de julho a dezembro de 2012. As etapas da pesquisa foram divididas em cinco procedimentos: 1- Uso de acionadores e mouses adaptados; 2- Uso de teclados adaptados; 3- Confecção de pranchas de comunicação suplementar e alternativa; 4- Utilização da prancha em ambientes naturais e 5-Capacitação dos familiares para o uso dos recursos. Os resultados indicaram que os recursos da TA possibilitaram aos alunos maior independência comunicativa, assim como possibilidades de interação com o contexto social, familiar e escolar.

Palavras-chave: Tecnologia assistiva. Comunicação suplementar e alternativa. Inclusão
\end{abstract}

ABSTRACT: The objective of this work was to insert resources and procedures of assistive technology in the care of students with disabilities. Attended two students aged 17 and 19 years, diagnosed with chronic non-progressive encephalopathy, without cognitive impairment, auditory and visual, not verbal language. Students attend resource room multifunctional, speech therapy and music therapy visits in a Core Support Integrated Care Specialized Education. The gathering took place in the period from July to December 2012. The steps of the research were divided into five steps: 1 - Using Triggers and mice adapted; 2 - Use of adaptive keyboards, 3 - Making planks augmentative and alternative communication; 4 - Use plank in natural and 5 - Training of family for the use of resources. The results indicated that the resources of the TA allowed students greater independence communicative as well as possibilities for interaction with the social, family and school.

Keywords: Assistive technology. Alternative and augmentative communication. Inclusion.

SAMESHIMA, Fabiana Sayuri; SILVA, Felipe Raphael Paiva da; LIMA, Nayelin Cristina Pereira; GONÇALVES, Flávia Regina. Tecnologia assistiva de baixo custo no atendimento de alunos com deficiência física. Informática na Educação: teoria e prática, Porto Alegre, v. 16, n. 2, p. 117-129, jul./ dez. 2013.

\author{
Fabiana Sayuri Sameshima \\ Felipe Raphael Paiva da Silva \\ Nayelin Cristina Pereira Lima \\ Flávia Regina Gonçalves \\ Unisalesiano de Lins/SP
}

\section{Introdução}

0 ser humano possui recursos verbais e não-verbais, que na interação interpessoal, se misturam e se completam. Para nos comunicarmos fazemos uso da palavra, da fala, porém a comunicação pode ir mais além tendo como complemento a expressão facial e os gestos, no entanto a comunicação é complementada por vários elementos comunicativos que nos permite compreender e ser compreendido.

Sem comunicação, cada um de nós seria como um mundo isolado. Comunicar é tornar comum, podendo ser um ato de mão única, como transmitir, ou de mão dupla, como compartilhar, dessa forma é a representação de uma realidade que serve para partilhar emoção, sentimento e informação. 
Quem comunica é a fonte e, do outro lado, está o receptor. O que se comunica é a mensagem. Pode ser vista, ouvida, tocada. As formas como as idéias são representadas são chamadas de signos. Em conjunto, formam os códigos: língua portuguesa, código Morse, Libras ou sinais de trânsito. "Os meios são usados pelos interlocutores para transmitir sua mensagem" (BORDENAVE, 2006).

Indivíduos acometidos por algum tipo de deficiência, ou dificuldade de se comunicar por meio da fala, podem encontrar barreiras que dificultam o processo de comunicação e interação entre as pessoas no meio em que convivem. Dessa forma, necessitarão de algum auxílio que facilitem e propiciem uma nova forma de comunicação com o mundo.

Dentre as tecnologias que garantam a acessibilidade e independência comunicativa, pontua-se a comunicação suplementar e alternativa (CSA), uma área que tem contribuído para facilitar e efetivar a comunicação das pessoas com ausência ou prejuízo da fala.

A comunicação alternativa envolve o uso de gestos manuais, expressões faciais e corporais, símbolos gráficos, fotografias, gravuras, desenhos, linguagem alfabética e ainda objetos reais, miniaturas, voz digitalizada, dentre outros, como meio de efetuar a comunicação face a face de indivíduos incapazes de usar a linguagem oral. Ela é considerada como uma área que se propõe a compensar temporária ou permanentemente a dificuldade do indivíduo em se comunicar. Considerando a realidade socioeconômica do nosso país, falar em comunicação ampliada e alternativa não pode se restringir apenas ao uso de metodologias específicas ou recursos comercializados, muitas vezes de alto custo (ITS BRASIL, p.25, 2008).

Outra definição é designada por Von Tetzchner e Jensen (1996), na qual a Comuni- cação Suplementar e Alternativa refere-se a todas as formas de comunicação que possam complementar, suplementar e/ou substituir a fala. Dirige-se a cobrir as necessidades de recepção, compreensão e expressão da linguagem e, assim, aumentar a interação comunicativa dos indivíduos sem oralidade.

A CSA é uma das categorias da Tecnologia assistiva, um termo utilizado para identificar todo o arsenal de recursos e serviços que contribuem para proporcionar ou ampliar habilidades funcionais de pessoas com deficiência e concomitantemente a promoção da vida independente e inclusão.

Os recursos e serviços da área da tecnologia assistiva são um direito adquirido pelo cidadão, amparado pela lei, no Art.61 do Decreto 5296, de dezembro de 2004, que garante: "Produtos, instrumentos, equipamentos ou tecnologia adaptados ou especialmente projetados para melhorar a funcionalidade da pessoa portadora de deficiência ou com mobilidade reduzida, favorecendo a autonomia pessoal, total ou assistida".

No Brasil, o Comitê de Ajudas Técnicas CAT, instituído pela PORTARIA No 142, DE 16 DE NOVEMBRO DE 2006 propõe o seguinte conceito para a tecnologia assistiva:

Tecnologia Assistiva é uma área do conhecimento, de característica interdisciplinar, que engloba produtos, recursos, metodologias, estratégias, práticas e serviços que objetivam promover a funcionalidade, relacionada à atividade e participação, de pessoas com deficiência, incapacidades ou mobilidade reduzida, visando sua autonomia, independência, qualidade de vida e inclusão social (CAT, p.15, 2007).

É também definida como uma ampla gama de equipamentos, serviços, estratégias e práticas concebidas e aplicadas para minorar os 
problemas encontrados pelos indivíduos com deficiências (COOK; HUSSEY, 2002). Os mesmos autores dividem o nível de complexidade e custo da tecnologia assistiva em recursos de baixa e alta tecnologia. Recursos de baixa tecnologia são os mais simples, que não fazem uso de energia, portanto, apresentam função limitada, tendo como vantagem maior disponibilidade, baixo custo e menor treinamento para o seu uso. Os recursos de alta tecnologia são mais complexos, multifuncionais, envolvendo sistemas computadorizados, operados por meio de programas especiais de softwares, podendo ser usados por alunos com deficiências de fala e dificuldade de movimentos para acesso ao computador.

Além da comunicação suplementar e alternativa, a TA engloba áreas como: adaptações e acesso ao computador, equipamentos de auxílio para déficits sensoriais, adaptações de postura, adaptações de jogos e atividades de brincadeiras nas diferentes situações como na escola, casa e outros ambientes, permitindo a possibilidade de inclusão social e escolar.

A tecnologia assistiva surge para a pessoa com deficiência, em muitos casos, como um elemento essencial que estimula a construção de novos caminhos e possibilidades para o seu aprendizado e desenvolvimento. À medida que se situa como instrumento mediador, disponibiliza recursos para participação de pessoas com deficiência, pois permite que ela interaja, relacione-se e possa competir em seu meio com ferramentas mais poderosas (PERES, 2003; BERSCH, 2006).

Os recursos da tecnologia assistiva surgem como ferramentas eficientes, que auxiliam o processo de inclusão escolar de pessoas com deficiência. O uso tem sido muito incentivado como forma de escolarização adequada de alunos com necessidades especiais, dentre eles, os alunos com diagnóstico de paralisia cerebral
(MANZINI; DELIBERATO, 2007; BERSH; PELOSI, 2007; LOURENÇO, 2008)

A deficiência física tende a se tornar uma barreira para os processos de significação e construção de mundo para alunos com esse tipo de comprometimento. Dispor dos recursos de acessibilidade ajudaria a neutralizar as barreiras causadas pela deficiência além de inserir o indivíduo nos ambientes ricos para a aprendizagem.

É fundamental que ocorra uma interligação entre a família e a equipe de profissionais para a educação do atendido. Todos podem fornecer informações substanciosas para ser cada vez mais assertivos nas escolhas dos materiais e dos métodos e ter um bom desenvolvimento dos programas (MANZANO, 2001).

O ambiente escolar deve disponibilizar inúmeras formas de recursos e apoios de caráter mais especializado com outros profissionais para proporcionar um bom desenvolvimento ao aluno deficiente para que esse tenha acesso ao currículo, favorecendo assim o processo de ensino e aprendizagem.

\section{Objetivo}

O objetivo do presente estudo foi implementar a Tecnologia Assistiva de baixo custo, nos atendimentos fonoaudiológicos e sala de recurso multifuncional. Para atingir os desígnios deste trabalho, a abordagem foi qualitativa, na qual se fez necessário a presença de procedimentos que serão descritos ao longo do presente artigo. 


\section{Material e método}

\subsection{Procedimentos iniciais}

Os participantes desta pesquisa e seus familiares, responsáveis legais, receberam as informações pertinentes ao projeto, como: objetivos, procedimentos de coleta de dados, tempo de duração, resguardo da privacidade do participante e utilização dos dados para fins científicos, tendo concordado e assinado o termo de consentimento livre e esclarecido.

\subsection{Participantes}

Participou desta pesquisa uma fonoaudióloga, uma professora do $A E E$, três estagiários, sendo um de pedagogia e dois de terapia ocupacional, além de dois alunos com deficiência física.

O participante A do sexo masculino, 17 anos de idade, com diagnóstico médico de encefalopatia crônica infantil não progressiva, inserido no ensino fundamental, $4^{\circ}$ ano,. Não apresenta comprometimentos cognitivos, e padrões de audição e visão, dentro da normalidade. Comunica-se por meios de gestos e expressões corporais, além de vocalizações. É usuário de cadeira de rodas, apresentando comprometimentos dos membros superiores e inferiores, utilizando com predomínio a mão esquerda para realizar as atividades propostas. Frequenta o Atendimento Educacional Especializado há 18 meses, além de receber atendimento na área de Fonoaudiologia e Musicoterapia.

O participante $B$ do sexo masculino com 20 anos de idade, com diagnóstico médico de encefalopatia crônica infantil não progressiva, frequenta Educação de Jovens e Adultos. Não apresenta comprometimentos cognitivos, au- ditivos e visuais. Comunica-se somente por meio do olhar e sorriso. Recebe atendimento na sala de recurso e fonoaudiologia 10 meses. É usuário de cadeira de rodas, apresentando comprometimentos dos membros superiores e inferiores, com poucas condições de utilizar os membros superiores para a realização de atividades, devidos a contraturas e deformidades.

\subsection{Local}

As atividades foram desenvolvidas no Núcleo de Apoio Integrado ao Atendimento Educacional Especializado Profa Elizabeth Guedes Chinalli (NAIAEE), criado pelo decreto da Lei no 5418 de 08/09/2010, que atende crianças com deficiência física, auditiva, visual, intelectual, múltipla, transtorno invasivo do desenvolvimento e altas habilidades, com objetivos de: Promover a implantação de salas de recursos, nas escolas municipais; Orientar as Unidades de Ensino por meio de Assessoria, de âmbito municipal, de forma a promover o acesso, a participação e aprendizagem dos alunos com deficiências, transtornos globais e do desenvolvimento de altas habilidades.

Além de oferecer aos alunos atendimento compatíveis com suas necessidades individuais; Oportunizar cursos de formação de educação inclusiva, aos profissionais da educação da Rede Municipal de Ensino; Garantir a continuidade de escolarização, nos níveis mais elevados do ensino; Melhorar a qualidade do ensino inclusivo por meio do aprimoramento do processo pedagógico no âmbito escolar; Considerar o aluno com deficiência como sujeito do processo de aprendizagem e ser de possibilidades; Garantir a interlocução entre o ensino regular e a educação especial no sentido de promover a aprendizagem de todos os alunos. 
O núcleo oferece atendimentos nas áreas de Educação e saúde, contemplando sete salas de recurso, fonoaudiologia, fisioterapia, terapia ocupacional, psicologia, musicoterapia e educação física.

\subsection{Materiais e instrumentos de pesquisa}

Foram utilizados durante os atendimentos os seguintes materiais como: acionadores de pressão e tração, mouses adaptados; teclados adaptados; pranchas de C.S.A; vocalizador GO talk; software Boarmaker; computadores e notebook.

Para o registro das informações, foram utilizadas técnica de vídeo e caderno de registro. A coleta ocorreu durante os atendimentos fonoaudiológicos e pedagógicos no período de julho a dezembro de 2012, no NAIAEE.

\subsection{Procedimentos de coletas de dados}

Para a realização da implementação dos recursos da TA, foram realizados encontros sistemáticos com a professore para pensar na escolha do material, considerando a dificuldade e potencialidade de cada aluno em sua individualidade.

Os materiais foram confeccionados no Núcleo com a supervisão da fonoaudióloga, com experiência em formação de professores e recursos, técnicas e procedimentos para a inclusão de alunos com deficiência.

Os procedimentos de coleta de dados foram divididos em cinco etapas, sendo elas: 1- Uso de acionadores e mouses adaptados; 2- Uso de teclados adaptados; 3- Confecção de Pran- chas de Comunicação Suplementar Alternativa (CSA), 4- Utilização da Prancha de CSA nos ambientes naturais, 5 - Capacitação dos familiares para o uso dos recursos. Os procedimentos serão descritos sucintamente a seguir:

\subsubsection{Uso de acionadores e mouses adaptados}

Os alunos participantes do estudo apresentavam dificuldades de acesso ao computador e outros equipamentos nas aulas de informática. Desse modo, houve a necessidade de se pensar em procedimentos e recursos para suprir esta lacuna.

Uma forma de garantir o acesso às atividades digitais, os mouses e acionadores adaptados, foi o ponto de partida para o processo. Neste sentido, foi firmada uma parceria com uma universidade, para a capacitação dos estagiários, na confecção desses materiais.

A capacitação foi realizada por um profissional da engenharia, durante o período de cinco meses. Neste tempo, foi possível construir 14 mouses e 14 acionadores, que foram utilizados nas terapias, além da distribuição nas demais escolas municipais de ensino. Estes recursos possibilitaram aos alunos com deficiência, manipular o computador de forma mais independente e autônoma, garantindo a participação dos mesmos nas atividades desenvolvidas nas aulas de informática.

Após a confecção dos materiais, foram trabalhadas estratégias de uso e manipulação adequada dos acionadores e mouses adaptados. Para esta atividade foi utilizado um roller mouse adaptado com materiais de baixo custo, confeccionado com o apoio de latas de biscoitos e embalagens de desodorante, assim como, o uso de acionadores de tração e pressão, também confeccionados com materiais de 
baixo custo, no qual foram utilizados potes de sorvete e tampas de remédio, como demonstram as fotos 1 e 2 .

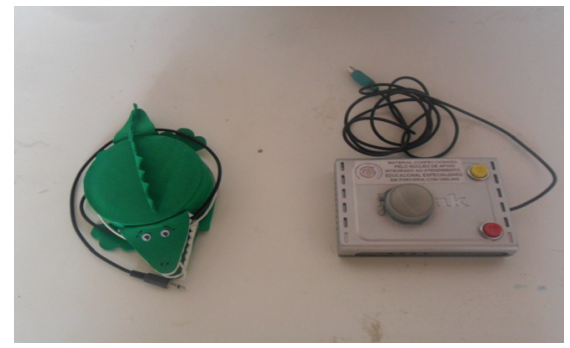

Foto 1: Acionador de tração e mouse adaptado Fonte: Do próprio autor

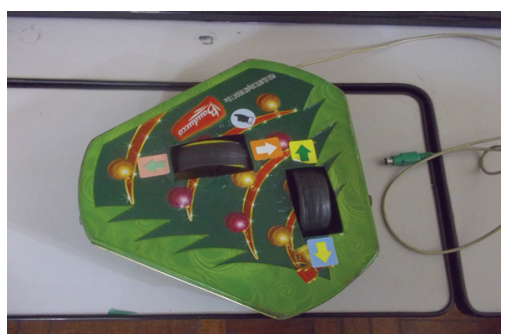

Foto 2: Roller mouse adaptado Fonte: Do próprio autor

\subsubsection{Uso de teclados adaptados}

Os alunos envolvidos na pesquisa apresentavam dificuldades em se comunicar por meio da fala, havendo a necessidade de se pensar em ações que facilitassem o processo de comunicação e interação nos ambientes naturais. Dessa forma, foram planejados atendimentos clínicos com a participação da fonoaudióloga e das estagiárias de Terapia Ocupacional com o objetivo de introduzir a comunicação suplementar e alternativa para os dois adolescentes com paralisia cerebral.

Uma das estratégias que facilitou o acesso ao computador, além dos mouses e acionadores adaptados, foi à inserção de um teclado adaptado, confeccionado pela estagiária de terapia ocupacional, composto de cores e letras ampliadas, para facilitar a compreensão, acesso e atenção dos alunos na escolha dos estímulos. Essa acessibilidade ao computador proporcionou independência e autonomia para a escolha dos estímulos para a composição das pranchas de CSA. A seguir, foto do teclado adaptado:

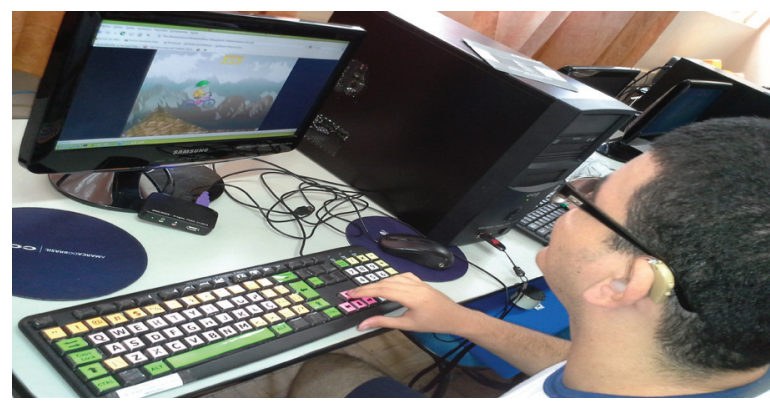

Foto 3: Teclado adaptado

Fonte: Do próprio autor

\subsubsection{Confecção de pranchas de co- municação suplementar e alterna- tiva}

Foram construídas duas pranchas de CSA com o uso do software Boardmaker. Para esta atividade, os próprios alunos manipularam o software com independência e tiveram acesso ao computador com o apoio dos mouses, acionadores e teclados adaptados que consistiam de diferenciação de cores nas letras, números e teclas de funções, além da ampliação do tamanho das letras. Para a seleção dos símbolos, foi necessário fazer um levantamento de informações, que suprissem a necessidade comunicativa nos diferentes ambientes. Dessa maneira foram colhidas informações sobre o conteúdo pedagógico do professor do AEE, das sessões de fonoaudiologia, e dos temas familiares. 
Após a coleta de informações, os participantes confeccionaram as pranchas de CSA durante os atendimentos fonoadiológicos, e foram divididas em categorias, sendo: pessoas, verbos, alimentos, passeios, escola, família. $\mathrm{Na}$ foto 4, é possível observar a fonoaudióloga e participante $A$, selecionando os símbolos da prancha de CSA.

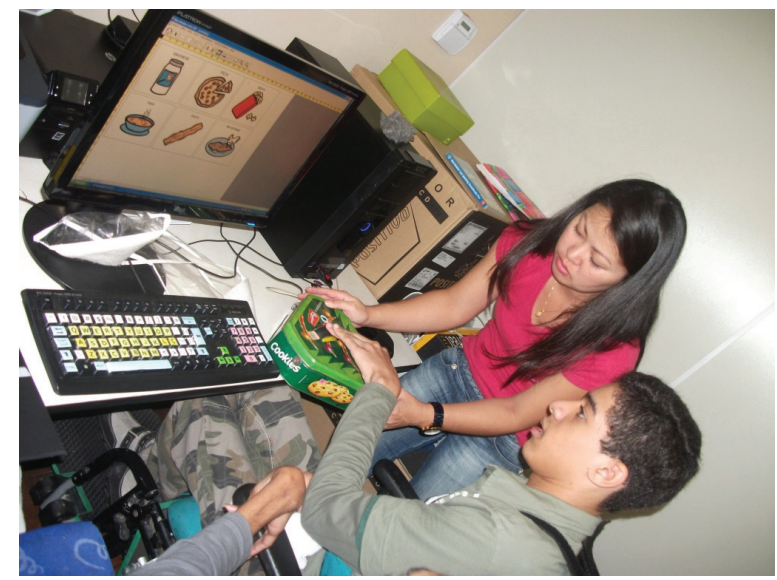

Foto 4: Confecção de pranchas de CSA Fonte: Do próprio autor

\subsubsection{Utilização da prancha de co- municação suplementar e alterna- tiva nos ambientes naturais}

Para a utilização das pranchas em ambientes naturais, os alunos foram levados para ambientes como: supermercados, feiras, praças e sorveterias para que pudessem fazer uso funcional da comunicação alternativa com diferentes interlocutores. Para que esta etapa fosse possível, os atendimentos eram planejados com antecedência, e estavam relacionados aos conteúdos desenvolvidos na sala de recurso, com o intuito de se atingir um objetivo pedagógico traçado pela equipe. A seguir as fotos
5 e 6, ilustram o passeio a feira, utilizando a prancha de CSA.
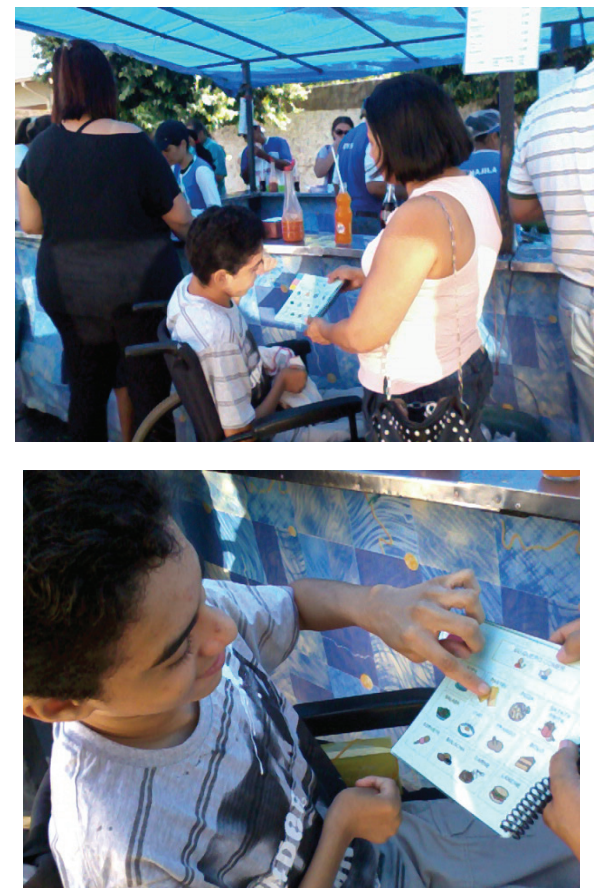

Fotos 5 e 6: Passeio a feira com uso de CSA Fonte: Do próprio autor

\subsubsection{Capacitação dos familiares para o uso dos recursos}

Na literatura da área da comunicação suplementar, é visível a necessidade da inserção da família no processo de avaliação, implementação e acompanhamento dos sistemas de CSA, nos diferentes ambientes (DELIBERATO; MANZINI, 1997; WALTER, 2006). Dessa forma, foram realizadas capacitações para os familiares com relação a CSA, por meio de encontros sistemáticos. Nesta etapa, os participantes tiveram um aprofundamento teórico, estabelecendo vínculos com a prática do dia a dia. Para tanto, foram utilizados materiais pedagógicos 
adaptados com o auxílio do software Boardmaker, que permitiu confeccionar uma variedade de materiais, desde os mais simples, aos mais elevados níveis. Esses materiais foram confeccionados durante oficinas que ocorriam semanalmente no NAIAEE.

Após a capacitação, os materiais foram inseridos na rotina diária, e as pranchas e figuras temáticas foram inseridas no ambiente familiar com o intuito de promover a comunicação e interação dos alunos sem linguagem oral, além de ser um sinalizador da rotina diária de cada aluno no ambiente escolar, social e familiar. $\mathrm{Na}$ foto 7 é possível observar a participação da família, usuário e estagiária de terapia ocupacional, no uso da prancha de CSA em ambiente social.

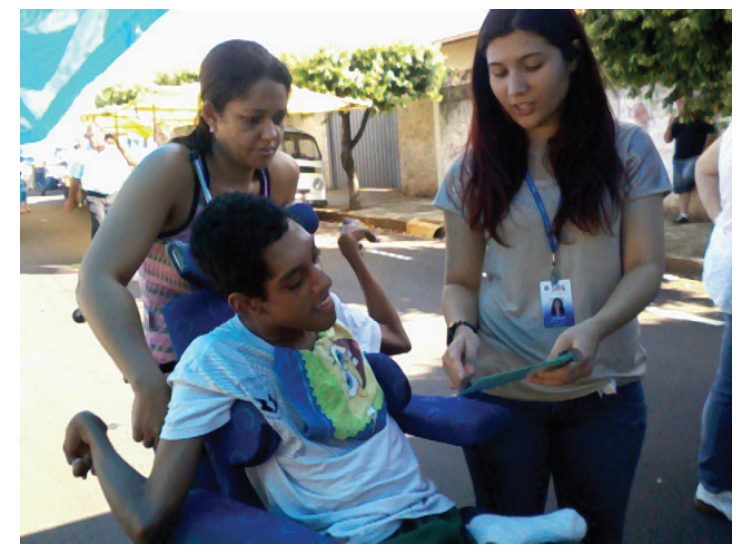

Foto 7: Participação da família Fonte: Do próprio autor.

\section{Resultados e discussões}

Os resultados proporcionaram ampliação das habilidades comunicativas com o uso das pranchas de comunicação e independência no acesso e manipulação do computador. O participante $A$, apresentou preferência pelo uso do acionador de pressão e utilizou na seleção das imagens do software Boardmaker para a composição de sua prancha. O participante B fez uso do acionador de tração, sendo que o mesmo foi preso em uma placa de Eucatex, posicionado na frente do aluno.

O aluno A utilizava o teclado sem a necessidade da adaptação, apresentando mais independência no manuseio da máquina, enquanto o participante $B$ emitia sons incompreensíveis, que necessitavam de mais atenção dos profissionais, apresentando também movimentos estereotipados de braços necessitando de um auxílio maior no acesso ao computador, com o apoio do teclado adaptado, além da ajuda das profissionais que posicionavam o teclado no local mais adequado, para que o mesmo trouxesse a mão a frente para apertar as teclas.

O uso desses equipamentos favoreceu a participação ativa dos alunos, na escolha das imagens selecionadas para a confecção das pastas de CSA. Nessas pastas foram selecionadas imagens de verbos, alimentação, passeios e outros já citados anteriormente.

Estes procedimentos foram importantes para que os alunos pudessem ter autonomia no uso do computador para a escolha dos estímulos visuais compostos por imagens, para a elaboração de um sistema de comunicação alternativa que facilitasse a comunicação e interação, visto que o objetivo desta etapa, era que a escolha dos estímulos gráficos que comporiam as pranchas de CSA de cada aluno, fosse de autonomia do próprio aluno.

Como discutido por Mello (1999), no âmbito da TA todo material e equipamentos tem a finalidade de proporcionar maior qualidade e independência na atividade funcional para pessoas com deficiência, podendo ser um instrumento que proporciona ações simples ou de grande sofisticação, que irá permitir ao individuo melhoras em suas ações, fundamentalmente na interação que irá manter com seu 
meio ambiente, dando autonomia e sentimento de ser capaz.

Para garantir a aceitação e o uso de forma funcional dos sistemas de CSA, são necessárias ações que visem à adoção dos recursos não somente pelo interlocutor com deficiência sem linguagem falada, mas por todos interlocutores, em seus ambientes naturais. A literatura vem pontuando que mais importante do que a disponibilidade dos recursos de CSA é a presença de interlocutores interessados em interagir e acolher as mensagens da pessoa não-falante, sendo essenciais a aceitação e o incentivo ao emprego de diversas formas de comunicação (VON TETZCHNER et al., 2005; VON TETZCHNER, 2009).

Neste sentido, durante os passeios, os alunos conseguiram solicitar com apoio das pranchas objetos de compras como: pastéis na feira, refrigerantes, bolachas, salgadinhos e bolos, esse favorecimento da independência comunicativa, motivou os alunos e familiares, no uso dos recursos em ambientes naturais. As famílias relataram melhora no entendimento de solicitações, vontades e relatos em situações cotidianas com o apoio das pastas de comunicação.

Para Deliberato (2010), a implementação de um sistema de comunicação suplementar e alternativo para alunos com distúrbios da linguagem poderia favorecer não só a ampliação da fala já existente, mas também contribuir para a organização da linguagem nos seus diferentes aspectos (VON TETZCNHER, 2003, 2009; VON TETZCNHER et al., 2005).

Pesquisas discutiram que esses sistemas são fundamentais para ampliar as habilidades comunicativas, principalmente as possibilidades expressivas de alunos com deficiência sem a possibilidade de utilizar a linguagem falada em diferentes ambientes. (SAMESHIMA, 2006,
2011; GUARDA, 2007; DELIBERATO; SILVA, 2007; DELIBERATO, 2009).

A professora do AEE conseguiu desenvolver as atividades pedagógicas com o apoio das figuras de CSA, o que possibilitou em uma nova forma de trabalho, sendo esta mais dinâmica, compreensível e de acordo com as possibilidades e necessidades dos alunos. Dessa forma, os recursos utilizados neste trabalho, possibilitaram independência motora, comunicativa para os alunos em questão, além de ampliar as possibilidades de interação com a sociedade, enfatizando também a amplitude desses recursos nos ambientes escolares.

É importante ressaltar que o professor tenha condições de criar suas próprias estratégias em favor do aprendizado do aluno com deficiência; mas, para isso, ele deve conhecer seus alunos no que se refere às habilidades $e$ necessidades de comunicação, motoras, cognitivas e de linguagem, para que possa elaborar suas atividades adequadamente (DE PAULA, 2007; ROCHA, 2010). Conhecendo as características de seus alunos, o professor pode selecionar instrumentos ou recursos mais adequados frente aos objetivos preestabelecidos para a mediação da aquisição de habilidades para o processo de desenvolvimento da leitura e escrita (DÉBORA, 2007, 2009; ROCHA, 2010).

Falar do uso funcional da prancha (visitas ao supermercado, feira), vinculo com

\section{Conclusão}

Este trabalho se baseou em uma proposta de recursos e serviços multidisciplinares com a parceria entre professor do AEE, fonoaudiólogo, estagiários de terapia ocupacional e pedagogia, enaltecendo a importância de uma equipe no processo de inclusão de alunos com deficiência. 
Os resultados deste trabalho reforçam a ideia de que o trabalho com comunicação suplementar e alternativa deve ser feito em equipe, baseado na cooperação e participação de todas as pessoas envolvidas no processo educacional (CAPELLINI, 2005; DELIBERATO, 2009; SAMESHIMA et al., 2009; SAMESHIMA, 2011).

De acordo com Deliberato (2009, 2010), essa equipe deverá ser formada pelo usuário, sua família, demais interlocutores atuantes, como, por exemplo, as pessoas da escola e os profissionais da saúde, sobretudo o fonoaudiólogo, o qual deverá coordenar e gerenciar as ações terapêuticas e as ações, nos demais ambientes, de sorte a favorecer a funcionalidade dos recursos a serem introduzidos. Desse modo, cabe enfatizar a importância da atuação do fonoaudiólogo nos programas com as escolas, a fim de garantir às crianças e aos jovens a inclusão social e escolar. Cabe ressaltar que neste trabalho, o gerenciamento de cada etapa de pesquisa, foi supervisionado por uma fonoaudióloga que atua na área de CSA há mais de 13 anos, e que conseguiu unir diferentes áreas do conhecimento, respeitando o conhecimento, opiniões e momento de cada profissional.

Esse estudo demonstrou que tanto a Comunicação Suplementar e/ou Alternativa como os mouses e acionadores proporcionaram aos alunos acesso ao computador de forma que os mesmos por meio de estímulos dados pelos profissionais puderam responder de forma satisfatória a estes, além de pssibilitar adaptações das atividades pedagógicas sem modificar seu verdadeiro objetivo e conteúdo, apenas transformando-a em mais acessível em prol de favorecer a maior independência e autonomia de alunos com deficiência inseridos nas escolas da rede pública de ensino.

\section{Referências}

BERSCH, R. Tecnologia assistiva e educação inclusiva. In: Ensaios Pedagógicos, Brasília: SEESP/ MEC, p. 89-94, 2006.

BERSCH, R. C. R.; PELOSI, M. B. Portal de ajudas técnicas para educação: equipamento e material pedagógico para educação, capacitação e recreação da pessoa com deficiência física: tecnologia assistiva: recursos de acesssibilidade ao computador. Brasília: ABPEE-MEC: SEESP. 66p. 2007.

BORDENAVE, Juan E. D. O que é comunicação. São Paulo: Brasiliense, 2006.

BRASIL. Decreto no 5.296, de 02 de dezembro de 2004 - DOU de 03/12/2004. http://www.planalto. gov.br/ccivil/_ato2004- 2006/2004/decreto/d5296.htm. Acesso em 11 de novembro 2008.

CAPELLINI, V. L. M. F. Avaliação das possibilidades do ensino colaborativo no processo de inclusão escolar do aluno com deficiência mental. 2005. Tese (Doutorado em Educação Especial) - Universidade Federal de São Carlos. São Carlos, 2005. 
CAT- Comitê de Ajudas Técnicas. Ata da Reunião VII, de dezembro de 2007 do Comitê de Ajudas Técnicas. Secretaria Especial dos Direitos Humanos da Presidência da República (CORDE/SEDH/PR), 2007. Disponível em: <http:// http://www.mj.gov.br/corde/comite.aspAcesso em: 16 maio. 2010.

COOK, A. M.; HUSSEY, S. M. Assistive technologies: principals and practice. 2ed. St. Louis, Missouri: Mosby, 523p. 2002.

DE PAULA, R. Desenvolvimento de um protocolo para avaliação de habilidades comunicativas de alunos não-falantes em ambiente escolar. 2007. Dissertação (Mestrado em Educação)- Universidade Estadual Paulista, Faculdade de Filosofia e Ciências, 2007.

DELIBERATO, D. Comunicação alternativa: recursos e procedimentos utilizados no processo de inclusão do aluno com severo distúrbio na comunicação. In: SHEILA ZAMBELLO DE PINHO; JOSE ROBERTO CORRÊA SAGLIETTI. (Org.). Núcleo de Ensino. São Paulo: Cultura Acadêmica, v. 1, p. 366-378, 2007.

- Comunicação alternativa na escola: habilidades comunicativas e o ensino da leitura e escrita. In: DELIBERATO, D.; GONÇALVES, M. J.; MACEDO, E.C. (Orgs). Comunicação alternativa: teoria, prática, tecnologias e pesquisa. São Paulo: Memnon Edições Científicas, p. 235-243, 2009.

Caracterização das habilidades expressivas de um aluno usuário de comunicação alternativa durante intervenção fonoaudiológica. 2010. 178 f. Tese de Livre-Docência - Faculdade de Filosofia e Ciências, Universidade Estadual Paulista, Marília, 2010.

DELIBERATO, D.; MANZINI. E. J. Comunicação Alternativa: delineamento inicial para implementação do Picture Communication System (P.C.S.). Boletim do C.O.E.. Marília, no 2, p. 29-39, 1997.

DELIBERATO, D.; SILVA, A. N. Habilidades expressivas de alunos não falantes no reconto de histórias. In: NUNES, L. R. O. P.; PELOSI, M. B.; GOMES, M.R. (Org.). Um retrato da comunicação alternativa no Brasil: relatos de pesquisas e experiências. $1^{a}$ ed. Rio de Janeiro: Quatro Pontos, 2007, v.1, p.66-76.

DÍAZ BORDENAVE, J. E. O que é comunicação. São Paulo: Brasiliense, 2006.

GUARDA, N. S. Caracterização dos enunciados de um aluno não-falante com paralisia cerebral durante o reconto de histórias com e sem o tabuleiro de comunicação suplementar e alternativa. 2007. 158 f. Dissertação (Mestrado em Educação) - Universidade Estadual Paulista, Marília, 2007.

INSTITUTO DE TECNOLOGIA SOCIAL (ITS BRASIL). Tecnologia Assistiva nas Escolas. Recursos básicos de acessibilidade sócio-digital para pessoas com deficiência. São Paulo: Microsoft- Educação, 2008. 
LOURENÇO, G. F. Protocolo para Avaliar a Acessibilidade ao Computador para Alunos com Paralisia Cerebral. 2008. 208f. Dissertação (Mestrado em Educação Especial (Educ. do Indivíduo Especial) - Universidade Federal de São Carlos. São Carlos. 2008.

MANZINI, E. J.; DELIBERATO, D. Portal de ajudas técnicas para educação: equipamento e material pedagógico especial para educação, capacitação e recreação da pessoa com deficiência física. Brasília: MEC. v.4. 71p. 2007.

MANZANO, E.S. Principios de educación especial. Madrid: Editorial CCS, 2001.

MELLO, M. A. F. TECNOLOGIA ASSISTIVA. In: GREVE, J. M. A.; AMATUZZI, M. M. Medicina de reabilitação aplicada à ortopedia e traumatologia. São Paulo: Rocca, 1999, p. 407-418.

PERES, R. C. N. C. O lúdico no desenvolvimento da criança com paralisia cerebral espástica. 2003. Tese (Doutorado em Educação) - Faculdade de Educação, Universidade de São Paulo, São Paulo, 2003.

ROCHA, A. N. D. Processo de prescrição e confecção de recursos de tecnologia assistiva para educação infantil, 2010. Dissertação (Mestrado em Educação)- Faculdade de Filosofia e Ciências da Universidade Estadual Paulista, Marília, 2010.

SAMESHIMA, F. S. Capacitação de professores no contexto de sistemas de comunicação suplementar e alternativa, 2011. 173 f. Tese (Doutorado em Educação) - Faculdade de Filosofia e Ciências, Universidade Estadual Paulista, Marília, 2011.

Habilidades expressivas de um grupo de alunos não-falantes durante atividades de jogos. 2006. 130 f. Dissertação (Mestrado em Educação) - Faculdade de Filosofia e Ciências, Universidade Estadual Paulista, Marília, 2006.

SAMESHIMA, F. S. et al. Comunicação alternativa e suplementar no ensino fundamental: adaptações das atividades pedagógicas de um aluno com deficiência física. In: MANZINI, E. J. et al. Linguagem e comunicação alternativa. Londrina: ABPEE, n. 2, p. 71-81, 2009.

VON TETZCHNER, S.; JENSEN, M.H. Augmentative and alternative communication. European perspective. London, UK, Whurr Publishers Ltda, 1996.

VON TETZCHNER, S. Enunciado de múltiplos símbolos no desenvolvimento da linguagem gráfica. In: NUNES, L.R.O.P. (Org.). Favorecendo o desenvolvimento da comunicação em crianças e jovens com necessidades educacionais especiais. Rio de Janeiro: Dunya, 2003. 171-201. 
VON TETZCHNER, S. Suporte ao desenvolvimento da comunicação suplementar e alternativa. In: DELIBERATO, D.; GONÇALVES, M. J.; MACEDO, E. C. (Org.). Comunicação alternativa: teoria, prática, tecnologias e pesquisa. São Paulo: Memnon Edições Científicas, 2009. p. 14-27.

VON TETZCHNER, S. et al. Inclusão de crianças em educação pré-escolar regular utilizando comunicação suplementar e alternativa. Revista Brasileira de Educação Especial, v.11, n. 2, p. 151-184, 2005.

WALTER, C. C. F. Avaliação de um programa de comunicação alternativa e ampliada aplicado por mães de adolescentes com autismo. 2006. Tese (Doutorado em Educação Especial)- Universidade Federal de São Carlos, São Carlos, 2006.

Submetido em 15 de agosto de 2013

Aprovado em 04 de setembro de 2013

Fabiana Sayuri Sameshima: Unisalesiano de Lins - Lins/SP - Brasil.

E-mail: fabianasameshima@yahoo.com.br

Felipe Raphael Paiva da Silva: Unisalesiano de Lins - Lins/SP - Brasil.

E-mail: felipepv3@gmail.com

Nayelin Cristina Pereira Lima: Unisalesiano de Lins - Lins/SP - Brasil.

E-mail: nayelinlima@hotmail.com

Flávia Regina Gonçalves: Unisalesiano de Lins - Lins/SP - Brasil.

E-mail: flavia_regina.msn@hotmail.com 